\title{
Desenvolvimento de uma salada de frutas: da pesquisa de mercado à tecnologia de alimentos
}

\author{
Fruit salad development: from market research to food technology
}

Wilton Soares CARDOSO ${ }^{1 \star}$, Flávia de Abreu PINHEIRO², Ronaldo PEREZ ${ }^{2}$, Talita PATELLI², Emanuel Roberto FARIA ${ }^{2}$

\begin{abstract}
Resumo
O entendimento das necessidades dos clientes e a utilização de tecnologia dos alimentos podem tornar uma ideia em um produto inovador. O objetivo deste trabalho foi estudar, por meio de uma pesquisa de mercado, a oportunidade de um novo produto e, posteriormente, elaborar uma salada de frutas frescas, utilizando técnicas de processamento mínimo com métodos combinados. A pesquisa de mercado foi realizada na região metropolitana de Belo Horizonte - MG para estudar o mercado potencial e avaliar a aceitação de uma salada de frutas pronta e embalada. No processo de desenvolvimento do produto, foram selecionadas três formulações, para avaliação sensorial, avaliadas a cada sete dias, durante 21 dias de armazenamento. $\mathrm{Na}$ análise de mercado, o produto salada de frutas foi aprovado, enquanto ideia, sendo considerada como ótima e original. Os clientes potenciais se apresentam como abertos a novidades de mercado e a novas marcas. Considera ainda como atributos de decisão de compra, em ordem de prioridade: preço, referência, necessidade, composição e ingredientes, valores nutricionais. No desenvolvimento da salada de frutas, todos os três tipos foram aceitos em análise sensorial com até 21 dias de armazenamento.

Palavras-chave: desenvolvimento de novos produtos; métodos combinados de conservação; processamento mínimo.
\end{abstract}

\begin{abstract}
Understanding the customers' needs and the use of food technology can make an idea become an innovative product. The goals of this study were to investigate, through a market research, the opportunity for a new product, and, subsequently, prepare an acceptable and fresh readyto-eat fruit salad using minimal processing and combined methods. The market research was carried out in the metropolitan region of Belo Horizonte - MG, Brazil to study the potential market and to assess the market opportunities for a packed, ready-to eat fruit salad. After the development of the product, three types of fruit salad were prepared and a sensory evaluation was carried out every seven days during 21 days of storage. The market research revealed that the fruit salad, as a potential product, was approved and considered excellent and original. The potential customers claimed that they are open to market novelties and new brands. They established the following as product attributes for purchasing decision in order of priority: price, reference, need, composition and ingredients, and nutritional values. It can be said that all three types of fruit salads prepared were accepted as a result of the sensory analysis of samples stored for up to 21 days.

Keywords: new products; innovation; combined methods; minimal processing.
\end{abstract}

\section{Introdução}

A inovação tornou-se um componente fundamental das empresas bem sucedidas de alimentos (VÁSQUEZ; SANTOS; ÁLVAREZ, 2001). A geração de ideias para novos produtos, e a consequente identificação de novas oportunidades, é uma necessidade que contribui para a melhoria do processo de desenvolvimento. A ideia passa a ser uma oportunidade quando incorpora informações que permitam a sua clara definição. O primeiro passo para que as informações possam ser associadas à ideia é a definição do segmento de mercado que a empresa pretende atingir. Uma mesma ideia certamente terá configurações diferentes de produtos para os diversos segmentos nos quais possa ser implementada. Encontrar uma oportunidade dentro de um segmento de mercado é a oportunidade de atender melhor à necessidade dos clientes (IAROZINSKI NETO; CANCIGLIERI JÚNIOR, 2003).

O entendimento pelas empresas das necessidades dos clientes muitas vezes é intuitivo, entretanto, em mercados competitivos, não se pode basear as decisões sobre novos produtos em suposições, elas precisam ser tomadas com base em dados e fatos confiáveis. As técnicas de estudo de mercado podem fornecer esta confiança e, assim, reduzir a probabilidade de fracasso no lançamento do produto (COHEN, 2000).

O estudo de mercado tem o objetivo de encontrar necessidades não atendidas ou mal atendidas pelos produtos existentes. Assim, quanto mais próximo das necessidades dos consumidores, maiores são as chances do produto ter sucesso

Departamento de Bioquímica, Universidade Federal de Viçosa - UFV, Rua Dr. Milton Bandeira, nº 204, apto 201, Centro, CEP 36570-000, Viçosa - MG, Brasil, 
no mercado (COHEN, 2000; MARCOS, 2001), mas esse longo caminho, nem sempre de sucesso, envolve, além das pesquisas em tendências de mercado, desenvolvimento em tecnologias de alimentos, testes de qualidade e marketing.

Nos últimos anos, os consumidores buscam o consumo de frutas frescas e seus produtos, como forma de obter uma dieta saudável com alto valor nutritivo, excelente qualidade sensorial, pouco processado, e estando ainda prontos para o consumo. Isto tem feito com que os produtos minimamente processados ganhem importância no mercado de frutas (SARZI; DURIGAN; ROSSI JÚNIOR, 2002; MATTIUZ; DURIGAN; ROSSI JÚNIOR, 2003). E produtos de frutas preservadas pelo método de barreiras ou método combinado têm potencial de mercado muito grande, devido a sua melhor retenção do sabor e textura originais, quando comparados a produtos desidratados (JAYARAMAN, 1988).

A técnica de preservação dos alimentos por processamento mínimo e métodos combinados é um método moderno utilizado para estender a vida de prateleira dos alimentos, permitindo melhor distribuição do produto, além de preservar a qualidade do sabor fresco (ALZAMORA et al., 1993). Pode ser aplicada a vários estágios da cadeia de distribuição do alimento, na estocagem, no processamento e/ou na embalagem (OHLSSON, 1994). Esta técnica consiste na combinação adequada de vários parâmetros de barreira, como redução na atividade de água, decréscimo no $\mathrm{pH}$, adição simples ou combinada de agentes antimicrobianos, moderado tratamento térmico e outros, que fazem com que se obtenham alimentos estáveis à temperatura ambiente e com baixo custo de produção (CHIRIFE; FAVETTO, 1992; WELTI-CHANES; VERGARA-BALDERAS; LOPEZ-MALO, 1994). A base tecnológica é a exposição simultânea das células microbianas vegetativas a vários fatores adversos de modo que o conteúdo de energia consumida nos processos homeostáticos sejam elevados e as células microbianas não tenham energia suficiente para o crescimento e reprodução (WELTI-CHANES et al., 1994).

O objetivo do trabalho foi estudar, através de uma pesquisa de mercado, a oportunidade de um novo produto e, posteriormente, utilizando as técnicas de processamento mínimo com métodos combinados ou de barreira, elaborar a salada de frutas fresca, pronta para o consumo, com vida útil aumentada, comprovada por meio dos testes sensoriais.

\section{Material e métodos}

\subsection{Metodologia da pesquisa de mercado}

A pesquisa de mercado foi realizada na região metropolitana de Belo Horizonte com o objetivo de diagnosticar o mercado potencial e avaliar a aceitação de uma salada de frutas pronta e embalada. A pesquisa realizada foi quantitativa a partir de entrevistas pessoais, mediante a aplicação de um questionário estruturado não disfarçado. A classificação dos consumidores seguiu os critérios determinados pela Associação Nacional das Empresas de Pesquisa (ANEP). O público alvo foi composto por adultos, com idades de 18 a 55 anos, pertencentes às classes $\mathrm{A}$ e $\mathrm{B}$, de ambos os sexos, frequentadores de delikatessen, supermercados, padarias, confeitarias e/ou ambientes gourmet. Segundo o IBGE (BRASIL, 2000), a classe A é formada por pessoas residentes (10 anos ou mais de idade) com rendimento nominal mensal maior que 20 salários mínimos, enquanto a classe B é caracterizada por pessoas residentes (10 anos ou mais de idade) com rendimento nominal mensal entre 10 e 20 salários mínimos. Para a área de execução do plano amostral, partiu-se dos seguintes dados populacionais: classe A com 77043 pessoas e classe B com 113439 pessoas (BRASIL, 2000). Para uma amostra de 110 elementos entrevistados, a pesquisa possui um grau de confiabilidade de $95 \%$, com margem de erro máximo de $8 \%$.

A abordagem foi feita na rua, em bairros residenciais das classes A e B de Belo Horizonte e através de entrevistas pré-agendadas nos estabelecimentos.

A coleta de dados foi feita através de entrevista pessoal, com 110 pessoas, tendo como instrumento de coleta, questionário estruturado não disfarçado, elaborado especificamente para atingir os objetivos deste estudo. Foi realizada por entrevistadoras de nível universitário, devidamente treinadas em técnicas de entrevistas e supervisionadas por uma empresa terceirizada de marketing e desenvolvimento. O questionário foi aplicado só após a apresentação conceitual da salada de frutas.

Os questionários estruturados abordaram os seguintes temas:

- Análise específica do produto salada de frutas: se o cliente potencial conhece algum produto similar à salada de frutas; opinião sobre a ideia de se produzir um produto com as características da salada de frutas; como o cliente potencial se avalia como um futuro consumidor da salada de frutas; em quais situações de consumo o cliente potencial da salada de frutas se identifica; razões apontadas pelo cliente potencial para não consumir a salada de frutas;

- Avaliações do comportamento do consumidor: como o cliente potencial se considera em relação às novidades do mercado;

- Grau de importância dos atributos na escolha dos produtos alimentícios de acordo com o cliente potencial: preço; marca; referência/indicação; sofisticação; embalagem; composição/ingredientes; necessidade e valores nutricionais; $\mathrm{e}$

- Perfil do consumidor potencial: sexo; atividade profissional; faixa etária; e faixas de renda familiar.

\subsection{Elaboração das saladas de frutas}

As saladas de frutas foram elaboradas na Fábrica Piloto de Conservas e no Laboratório de Novos Produtos do Departamento de Tecnologia de Alimentos, Universidade Federal de Viçosa - UFV.

As frutas utilizadas no presente estudo, banana-nanica, goiaba vermelha Paluma, mamão Formosa, maracujá-amarelo e manga Tommy, foram adquiridas no mercado local de Viçosa - MG. Todas as frutas apresentavam-se em grau ótimo de 
maturação, exceto a banana que se apresentava menos madura, estágio de maturação 4 (TADINI et al., 1998).

Para caracterização das frutas (peso, altura e espessura) pesaram-se 10 frutas ao acaso, em balança semianalítica, marca Micronal (São Paulo - SP), e também foram medidas por meio de um paquímetro a espessura e a altura dos frutos. Estas medidas tiveram como objetivo caracterizar e classificar a matéria-prima de acordo com a maturação.

Os experimentos foram realizados em diferentes condições de tratamento. Aqui apresentamos os resultados de três diferentes composições de caldas, avaliadas em tempos de armazenamento diferentes (1,7,14 e 21 dias): o tratamento 1: calda 1:10 relação polpa de maracujá/xarope com $0,4 \%$ de acidez; o tratamento 2: calda 1:10 relação polpa de maracujá/xarope com 0,6\% de acidez; e o tratamento 3: calda 1:15 relação polpa de maracujá/xarope com $0,4 \%$ de acidez.

Para preparação das caldas utilizaram-se açúcar cristalizado granulado, água e suco de maracujá. Para correção da acidez da calda, manteve-se constante a concentração de ácido ascórbico para todos os tratamentos (500 ppm) e utilizou-se ácido cítrico até atingir acidez desejada de 0,4 ou $0,6 \%$. Os acidulantes adicionados foram ácido cítrico anidro e ácido ascórbico de grau alimentício, provenientes da empresa Plury Química (Diadema - SP).

Aplicaram-se diferentes tipos de tratamento térmico à calda. Aqui apresentamos o de $85{ }^{\circ} \mathrm{C} / 5$ minutos, para garantir sua segurança microbiológica. Posteriormente, a calda foi resfriada em câmara fria a $6{ }^{\circ} \mathrm{C}$ para atingir estabilidade térmica, para posterior adição às frutas.

As frutas adicionadas às caldas (tratamentos) foram processadas dentro das técnicas de processamento mínimo, ou seja, de modo a evitar a contaminação e o escurecimento enzimático. As frutas foram lavadas em água corrente para eliminar partículas mais grosseiras, como terra e outros detritos, e posteriormente imersas por 15 minutos em água clorada (50 ppm) para diminuição da contaminação inicial. Todos os utensílios utilizados no preparo das frutas também foram sanitizados por solução de cloro 100 ppm.

As frutas foram descascadas manualmente e os cortes padronizados em cubos de $0,5 \mathrm{~cm}$ e rodelas de $0,5 \mathrm{~cm}$ de espessura. Os cubos e rodelas foram imersos por 30 segundos em água clorada (50 ppm) com o objetivo de remover o suco celular liberado e reduzir a contaminação microbiológica. Os pedaços de frutas foram posteriormente drenados em peneiras por 1 minuto. Pesaram-se os pedaços das frutas e a calda, de modo a manter a relação 1:1. Procurou-se manter a mesma quantidade das quatro frutas. As saladas foram acondicionadas em embalagens plásticas individuais e mantidas em temperatura refrigerada $\left(6^{\circ} \mathrm{C}\right)$ em câmara fria.

Para análise do rendimento das frutas, inicialmente pesaram-se as frutas inteiras e após o processamento pesaram-se os resíduos, como cascas, sementes e partes não aproveitáveis das frutas. Pela diferença de peso, estimou-se o rendimento para o processamento de salada de frutas.

\subsection{Análises físico-químicas e análise sensorial}

As análises físico-químicas foram realizadas com intenção de caracterizar as matérias-primas e acompanhar, ao longo do armazenamento, as transformações ocorridas nas frutas e nos tratamentos. As determinações de $\mathrm{pH}$, sólidos solúveis totais (SST em ${ }^{\circ}$ Brix) e acidez (ATT expressa em \% de ácido cítrico) foram realizadas de acordo com as Normas Analíticas do Instituto Adolfo Lutz (BRASIL, 1985).

$\mathrm{O} \mathrm{pH}$ das caldas foi determinado por potenciometria, medindo-se diretamente em um pHmêtro digital portátil, marca WTW modelo pH 330i. Os teores de sólidos solúveis das frutas e das caldas foram determinados por refratometria, à temperatura ambiente, utilizando-se um refratômetro portátil, marca Kilter, escala 0 - 100. A acidez foi calculada com base no ácido cítrico, principal ácido presente nas frutas. A relação sólidos solúveis totais/acidez total titulável (SST/ATT ou Ratio) foi obtida pela razão das medidas \%SST e \%ATT.

A análise sensorial foi realizada através de teste de aceitação. Como os parâmetros físico-químicos da salada de frutas variam com o tempo, há necessidade de analisar a aceitabilidade do produto nos diferentes tempos de armazenamento. Sendo assim, foram realizadas quatro análises sensoriais variando apenas o tempo de armazenamento do produto, $1,7,14$ e 21 dias. Os testes sensoriais foram realizados em cabines por 83 provadores não treinados, com idades entre 16 e 50 anos. Avaliou-se o aspecto sensorial "sabor" de três amostras de salada de frutas, de acordo com a escala hedônica de 9 pontos: 9 - gostei extremamente a 1 - desgostei extremamente.

\subsection{Análise estatística}

A análise estatística foi realizada de acordo com os procedimentos do Statistical Analysis System (SAS INSTITUTE, 2001) em esquema fatorial aninhado $(3 \times 4)(3$ tipos de saladas em 4 tempos de armazenamento), em delineamento inteiramente casualizado e os resultados obtidos pelas notas de cada provador foram avaliados por meio da Análise de Variância, ao nível de $5 \%$ de probabilidade.

\section{Resultados e discussão}

\subsection{Pesquisa inicial de mercado}

Como primeiro passo do processo de desenvolvimento de produtos, definiu-se conceitualmente o produto salada de frutas. Após este passo inicial e com a finalidade de avaliar o potencial da ideia, realizaram-se entrevistas junto aos consumidores.

A amostra de consumidores entrevistados é caracterizada por uma proporção de mulheres superior a dos homens, 57,7 e $42,3 \%$, respectivamente. A maioria dos entrevistados, $66,1 \%$, possui idade entre 25 e 50 anos. A faixa etária de 51 a 60 anos também aparece de forma significativa em 19,1\% dos entrevistados. Quanto às atividades profissionais há um público bem diversificado, predominado por empresários e profissionais liberais $(35,5 \%)$, sendo composto também por aposentados $(11,8 \%)$, seguido por executivos e consultores com 8,2 e 7,3\%, respectivamente. 
A maioria do grupo pesquisado possui renda familiar entre R \$ 4501 e R \$ 7500. Dos entrevistados, 26,4\% têm renda familiar de R $\$ 7501$ ou mais. Outra fatia do grupo, $21,8 \%$, está entre os que possuem renda familiar entre $\mathrm{R} \$ 3001$ e R $\$ 4500$. Em seguida, com 18,2\%, estão os que possuem renda familiar entre R $\$ 1500$ e R \$ 3000. Apenas 1,8\% dos entrevistados não quiseram informar a renda familiar. Com renda familiar acima de $R \$ 1500$ reais, os clientes identificados como potenciais estão posicionados prioritariamente nas classes B2, B1, A2 e A1. Conforme proposto, como potenciais consumidores desse produto.

Os entrevistados não puderam degustar a salada de frutas na ocasião da entrevista, mas assim mesmo, atraídos pela ideia, demonstraram interesse em se tornarem futuros consumidores, sendo que $70,9 \%$ afirmaram que certamente consumiriam ou sempre consumiriam o produto; $20,9 \%$ talvez consumiriam; e apenas $4,5 \%$ nunca consumiriam.

Avaliou-se o potencial de consumo da salada de frutas, identificando-se que a maior frequência ocorria no lanche ou sobremesa (42,7\%). É importante chamar a atenção para o índice de não identificação para uma situação de consumo, que por se tratar de um produto desconhecido apresentou índice de 42,7\% (Tabela 1), fato que vai exigir uma promoção do produto quando do seu lançamento.

Confirmando o índice apresentado em relação aos entrevistados que se mostraram interessados em se tornarem futuros consumidores, $95,5 \%$ não apresentaram razões para não consumirem o produto.

Com relação à pergunta "se o cliente potencial conhece algum produto similar à salada de frutas", $98,2 \%$ responderam não conhecer um produto similar no mercado. Destes, aproximadamente $90 \%$ reconhecem a ideia como original (boa ideia, inovadora, criativa e interessante), conforme Tabela 2.

Nas avaliações do comportamento do consumidor sobre como o cliente potencial se posiciona em relação às novidades do mercado, $71,8 \%$ dos entrevistados consideram-se abertos a novos produtos e a novas marcas, contrapondo aos $6,4 \%$ que se consideram abertos a novos produtos, mas são fieis às marcas. Apenas 2,7\% dos consumidores consideram-se irredutíveis em relação aos produtos e marcas. Consideram-se tradicionais com relação aos seus costumes $18,2 \%$, mas se posicionaram como sendo abertos a novas marcas.

Tabela 1. Freqüência das respostas dos clientes em relação à pergunta "em quais as principais situações de consumo o cliente potencial da salada de frutas se identifica".

\begin{tabular}{lcc}
\hline \multicolumn{1}{c}{ Opções } & Freqüência & $\%$ \\
\hline Lanche & 16 & 14,5 \\
Sobremesa & 31 & 28,2 \\
Refeições & 7 & 6,4 \\
No lazer & 8 & 7,3 \\
Outros & 1 & 0,9 \\
Não identificaram & 47 & 42,7 \\
Total & 110 & 100 \\
\hline
\end{tabular}

Tabela 2. Freqüência das respostas dos clientes que desconhecem um produto similar sobre a idéia de se produzir um produto com as características da salada de frutas.

\begin{tabular}{lcr}
\hline Opções & Freqüência & $\%$ \\
\hline Boa idéia & 68 & 61,8 \\
Criativa & 2 & 1,8 \\
Saudável & 1 & 0,9 \\
Importante & 1 & 0,9 \\
Indiferente & 1 & 0,9 \\
Inovadora & 6 & 5,5 \\
Interessante & 14 & 12,7 \\
Não interessou & 4 & 3,6 \\
Não sabe & 2 & 1,8 \\
Pouco prático & 2 & 1,8 \\
Prático & 7 & 6,5 \\
Tentadora & 1 & 0,9 \\
Total & 110 & 100,0 \\
\hline
\end{tabular}

Sobre as avaliações do grau de importância dos atributos (de nada importante a muito importante) dos produtos na ocasião de compra, tem-se os seguintes resultados. $\mathrm{O}$ atributo preço foi avaliado por $82,8 \%$ como "importante" e "muito importante" para o consumidor na ocasião de compra, apenas $5,5 \%$ dos consumidores atribuem o preço como sendo "nada importante".

$\mathrm{O}$ atributo de indicação ou referência é considerado pela maioria, $71,8 \%$, como "relativamente importante" e "importante", além de $15,5 \%$, que consideram a referência como "muito importante" para a escolha. Em relação à marca, 35,5\% consideram este atributo "importante", $24,5 \%$ consideram-no "relativamente importante", $20 \%$ como "muito importante" e $16,4 \%$ "pouco importante".

Quanto ao atributo sofisticação, 30\% consideram-no "importante", 29,1\% consideram-no "relativamente importante", $20 \%$ "pouco importante" e 13,6\% "muito importante".

A embalagem é um atributo considerado por $67,3 \%$ dos entrevistados como "importante" ou "muito importante". É recomendável chamar a atenção para o índice de consumidores que consideram a embalagem um item "relativamente importante" (20,7\%). O que leva a observar que a embalagem é um item observado por $88,2 \%$ dos consumidores.

A composição/ingredientes do produto é considerado "importante" ou "muito importante" pelo consumidor potencial, alcançando juntos o significativo índice de 90,9\%.

Em relação à necessidade, esta foi considerada pelo consumidor como uma condição "importante" ou "muito importante" na ocasião da compra $(76,4 \%)$, embora $20,9 \%$ admitiram a possibilidade de comprar por impulso ao considerarem este item como sendo "pouco importante" $(9,1 \%)$ ou "relativamente importante" (11,8\%).

Reforçando a importância da composição/ingredientes do produto, o atributo valores nutricionais é considerado "importante" ou "muito importante" pelo consumidor potencial, alcançando juntos o índice de 89,1\%. 
O cliente potencial do produto salada de frutas apresentouse como sendo aberto às novidades de mercado e a novas marcas e considera os atributos, preço, referência ou indicação, necessidade, composição e ingredientes, valores nutricionais como sendo os mais importantes na hora da decisão de compra. Embora não se destacando como atributo de grande importância para a decisão, o cliente potencial demonstrou grande sensibilidade para o atributo embalagem. Estas informações possibilitam à empresa o desenvolvimento de embalagem, de rótulo e de alegações de campanhas publicitárias que informem sobre características e propriedades do produto, de forma a elevar a expectativa no consumidor em relação ao produto e incentivar a compra (BEHRENS; SILVA, 2004).

\subsection{Etapas de desenvolvimento}

Com base nas premissas levantadas junto ao consumidor, passou-se à etapa de desenvolvimento do produto em escala de bancada, através de tecnologias aplicadas aos alimentos.

Na caracterização das frutas (Tabela3), não foram considerados alguns defeitos, pois a salada de frutas pode ser feita com frutas de mesa que não são aproveitadas no mercado, por apresentarem defeitos leves ou tamanhos inadequados, com exceção da banana que deverá se apresentar sem defeitos, pois estes aumentam a velocidade de oxidação e escurecimento da polpa.

O rendimento das frutas para o processamento da salada de frutas teve os seguintes resultados: mamão $67,0 \%$, manga $62,0 \%$, maracujá $44,0 \%$, goiaba $47,0 \%$ e banana $62,0 \%$. O conhecimento dos rendimentos é um dado muito importante para a indústria, pois assim é possível estimar a produtividade, perdas e também estimar o custo de produção e venda do produto. Deve-se ressaltar o aproveitamento dos resíduos da goiaba como alternativa para o aproveitamento máximo da fruta.

Nas análises físico-químicas, inicialmente, são apresentados os resultados do $\mathrm{pH}$, acidez e sólidos solúveis totais (SST) das caldas. Observa-se na Tabela 4 que o $\mathrm{pH}$ da calda, durante todo o período de armazenamento, manteve-se abaixo de 4,0. Este valor é desejável, visto que, abaixo deste $\mathrm{pH}$, não há crescimento de microrganismos deterioradores (FORSYTHE, 2002). O controle

Tabela 3. Caracterização das frutas em relação às médias das variáveis pesos, altura e espessura.

\begin{tabular}{lccc}
\hline Frutas & Peso $(\mathrm{g})$ & Altura $(\mathrm{cm})$ & Espessura $(\mathrm{cm})$ \\
\hline Manga & 284,6 & 10,4 & 8,8 \\
Goiaba & 196,9 & 8,2 & 7,0 \\
Mamão & 1580,2 & - & 11,0 \\
Banana & 133,5 & - & 3,7 \\
Maracujá & 204,7 & 9,6 & 7,9 \\
\hline
\end{tabular}

Tabela 4. Valores de $\mathrm{pH}$ dos três tipos de caldas, durante o período de armazenamento.

\begin{tabular}{cccccc}
\hline $\mathrm{pH}$ & Tempo 0 & 1 dia & 7 dias & 14 dias & 21 dias \\
\hline Tratamento 1 & 3,35 & 3,50 & 3,67 & 3,86 & 3,72 \\
Tratamento 2 & 3,18 & 3,25 & 3,56 & 3,75 & 3,56 \\
Tratamento 3 & 3,45 & 3,59 & 3,71 & 3,85 & 3,62 \\
\hline
\end{tabular}

da microbiota contaminante é, portanto, fator determinante na manutenção da vida de prateleira e segurança do produto fresco (FANTUZZI; PUSCHMANN; VANETTI, 2004).

$\mathrm{O}$ pH da calda aumentou durante a estocagem, devido à absorção de ácidos pelos frutos, contudo, nota-se um leve decréscimo no valor do $\mathrm{pH}$ no $21^{\circ}$ dia de armazenamento.

Na Figura 1 está descrito o comportamento da ATT das caldas. Pode-se observar que a acidez, em todos os tratamentos, teve comportamento semelhante, uma redução até o sétimo dia e depois se manteve constante até o $21^{\circ}$ dia.

O comportamento dos SST está descrito na Figura 2. A concentração inicial de SST das caldas é maior que a concentração inicial de SST das frutas que compõem o produto. Esta alta concentração exerce uma pressão osmótica sobre as frutas, o que favorece a perda de água, concentrando SST nas frutas. O ganho de água da calda, faz com que a concentração de SST inicial se dilua, diminuindo o teor de SST da calda. Além desta troca de água, existe a troca de açúcares, porém com uma taxa muito reduzida, devido à dificuldade de moléculas grandes, como o açúcar, atravessarem a membrana celular.

Analisando as Figuras 1 e 2, nota-se que, depois de estabelecido o equilíbrio, ainda há pequena variação de SST e ATT. Sugere-se que estas oscilações devam-se à continuidade do metabolismo celular das frutas minimamente processadas, ou seja, utilização de açúcares na respiração, síntese de açúcares

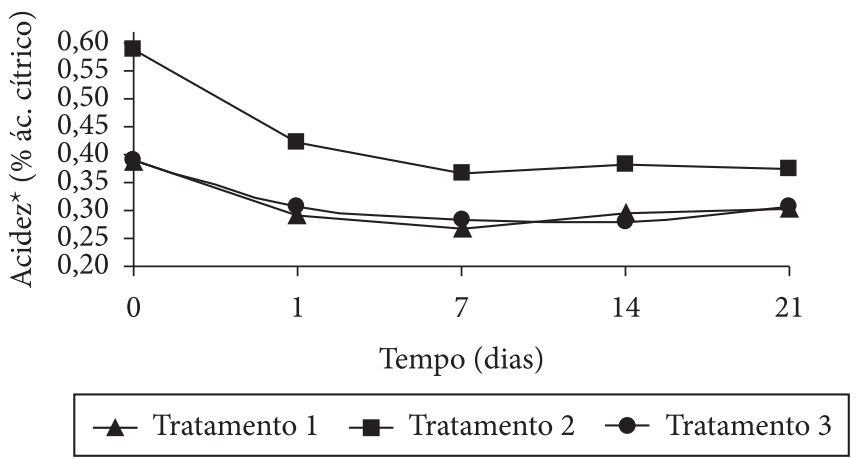

Figura 1. Comportamento das caldas, em relação à acidez, durante os 21 dias de armazenamento, à temperatura de $6{ }^{\circ} \mathrm{C}$. $* \%$ de acidez expressa em ácido cítrico.

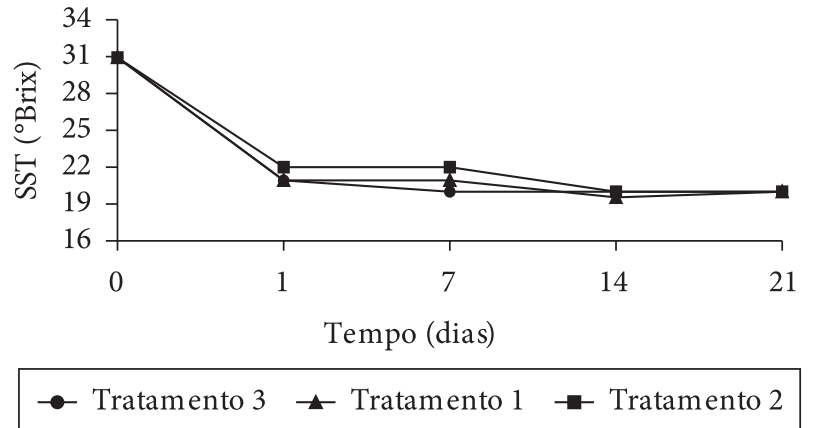

Figura 2. Comportamento das caldas, em relação à SST ( ${ }^{\circ}$ Brix), durante os 21 dias de armazenamento, à temperatura de $6{ }^{\circ} \mathrm{C}$. 
na interconversão amido-açúcar, utilização de ácido cítrico no ciclo de Krebs, uso do ácido ascórbico para evitar a oxidação enzimática. Estas variações, também, podem ser atribuídas às ocasionais irregularidades de maturação das frutas.

As frutas foram analisadas quanto à acidez (ATT) e sólidos solúveis totais (SST), e foi calculada a razão (SST/ATT), também denominada de "ratio", expressão muito utilizada na indústria de suco.

As Figuras 3 e 4 mostram o comportamento da acidez nas frutas durante o armazenamento para os 3 tratamentos.

Segue, nos gráficos abaixo (Figura 4, 5, 6e 7), o comportamento dos parâmetros de sabor, em relação à SST e a razão (SST/ATT) ou "ratio" nas frutas durante o tempo de armazenagem em câmara fria $\left(6^{\circ} \mathrm{C}\right)$. A razão (SST/ATT) ou "ratio" é um importante parâmetro qualitativo, pois dá o indicativo do sabor da fruta, uma vez que ele é consequência do balanceamento entre os constituintes de sabor doce e ácido desta.

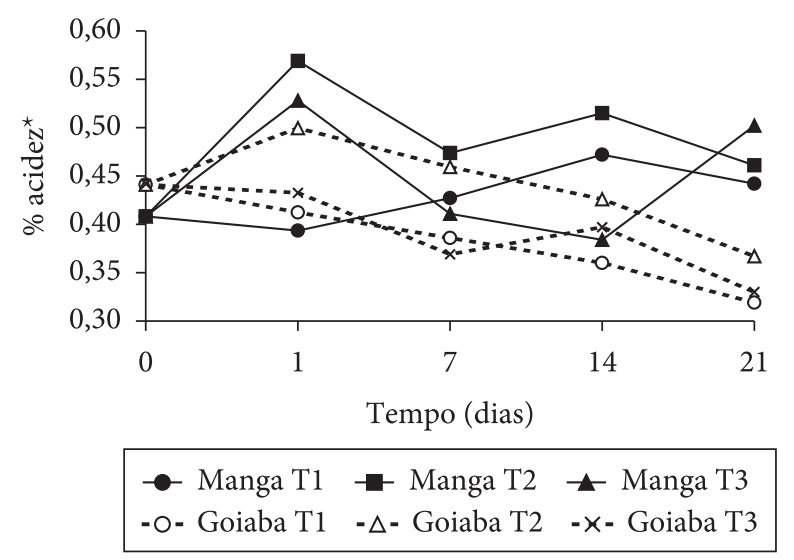

Figura 3. Comportamento das frutas em pedaços, manga e goiaba, em relação à acidez (ATT), durante o armazenamento à temperatura de $6{ }^{\circ} \mathrm{C}$. $*$ de acidez expressa em ácido cítrico.

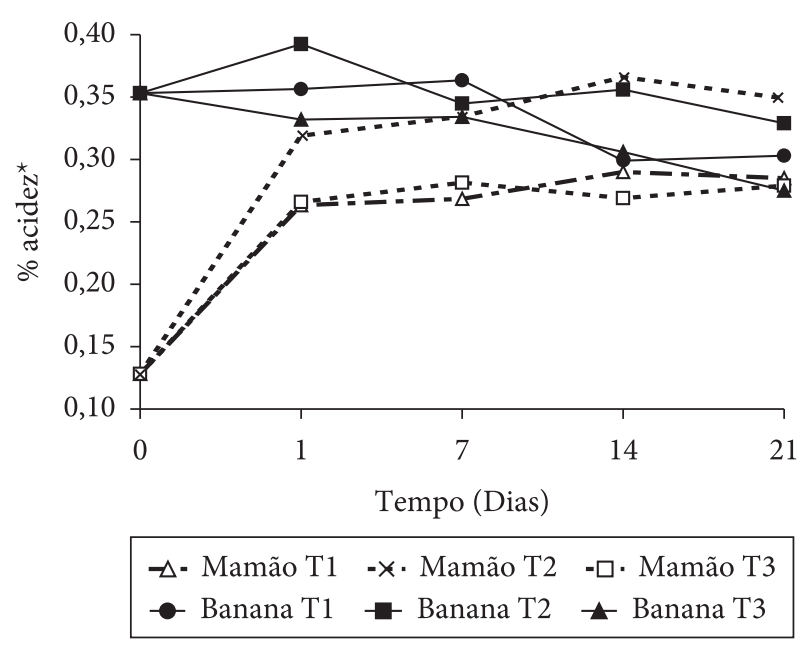

Figura 4. Comportamento das frutas em pedaços, mamão e banana, em relação à acidez (ATT), durante o armazenamento à temperatura de $6{ }^{\circ} \mathrm{C}$. $* \%$ de acidez expressa em ácido cítrico.
Frutos poderão se tornar sobremaduros, do ponto de vista de sabor, tanto pelo acúmulo de açúcares quanto pela diminuição da acidez e, assim, se tornarem pouco saborosos (MATTIUZ; DURIGAN; ROSSI JUNIOR, 2003).

A manga e a goiaba apresentaram a razão (SST/ATT) inicial semelhante, próximo de 20 (Figuras 5 e 6), no entanto, a razão (SST/ATT) final, depois de 21 dias, foi maior para a goiaba, entre 60 e 70. Como a concentração de SST foi a mesma para as duas frutas, a diminuição da acidez da goiaba foi mais pronunciada (Figura 3), seja pela perda de ácido da fruta (por reações enzimáticas ou para a calda) ou pela absorção de água pela fruta, sendo responsável pelo aumento da razão (SST/ATT).

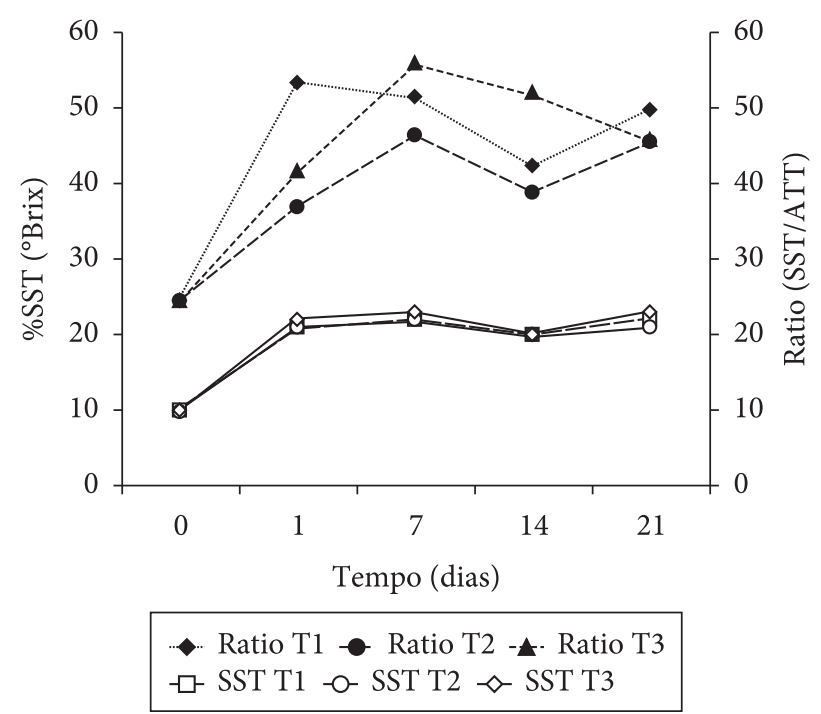

Figura 5. Comportamento da manga, nos três tratamentos, em relação à variação dos SST e da razão (SST/ATT), durante os 21 dias de armazenamento à temperatura de $6{ }^{\circ} \mathrm{C}$.
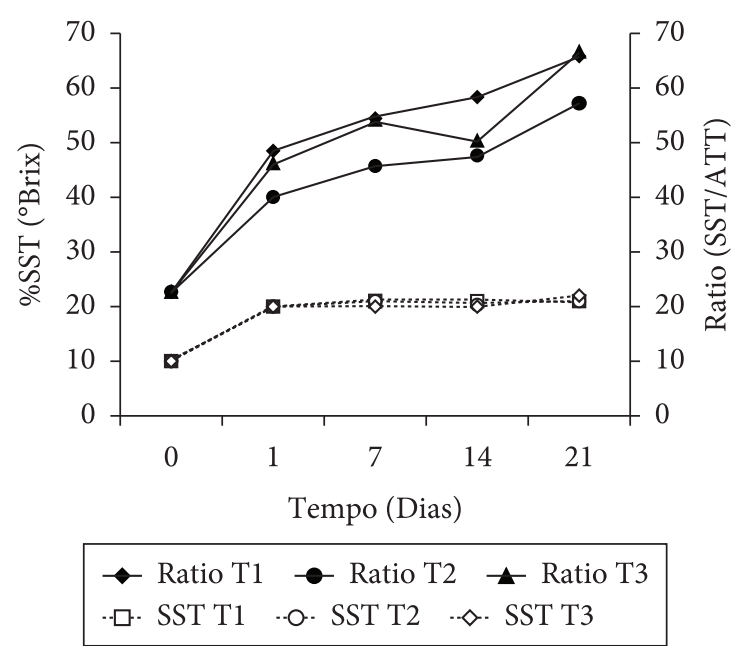

Figura 6. Comportamento da goiaba, nos três tratamentos, em relação à variação dos SST e da razão (SST/ATT), durante os 21 dias de armazenamento à temperatura de $6{ }^{\circ} \mathrm{C}$. 
A banana manteve o mesmo SST inicial até o $21^{\circ}$ dia de armazenamento (Figura 7), apresentou uma elevação da razão (SST/ATT), facilmente explicada pela diminuição de sua acidez (Figura 4).

O mamão, entre as frutas, foi o que apresentou menor SST (Figura 8), mas, devido à sua menor acidez (Figura 4), apresentou maior razão (SST/ATT) (70). Cabe ressaltar que o mamão foi a fruta que obteve maior aumento de SST, no entanto, o aumento na concentração de ácido foi proporcionalmente maior, favorecendo ao final um leve aumento ou até mesmo diminuição do "ratio".

O aumento dos SST é devido, em parte, à perda de água da fruta e à absorção de açúcares da calda. Devido ao fato da pressão osmótica realizada sobre a banana ser menor, consequente do seu alto teor SST, quando comparado com as outras frutas, e também à redução rápida dos SST da calda, devido ao aumento de água de outras frutas ou perda de açúcar, ocorreu uma estabilização de SST da banana com a calda. Não havendo, portanto, perda de água ou acúmulo de açúcar pela banana. Raoult-wack, Lenart e Guilbert (1994) verificaram que, em soluções com concentração inicial inferior a 40\%, predomina a incorporação de solutos nos produtos, enquanto numa concentração superior a esse percentual, há maior taxa de saída de água, ou seja, ocorre à desidratação propriamente dita.

A variação da razão (SST/ATT) durante o período de armazenamento das frutas ocorreu devido à variação de acidez, já que os SST se estabilizaram no primeiro dia. A manga e o mamão apresentaram grande variação do "ratio" durante o armazenamento para todos os tratamentos e as suas curvas não apresentaram comportamento crescente, como as curvas da goiaba e banana que mostraram aumento da razão (SST/ATT) com o armazenamento para todos os tratamentos.

\subsection{Aceitação sensorial do consumidor}

Após ter garantido a manutenção das características físico-químicas da salada de frutas, a próxima etapa do

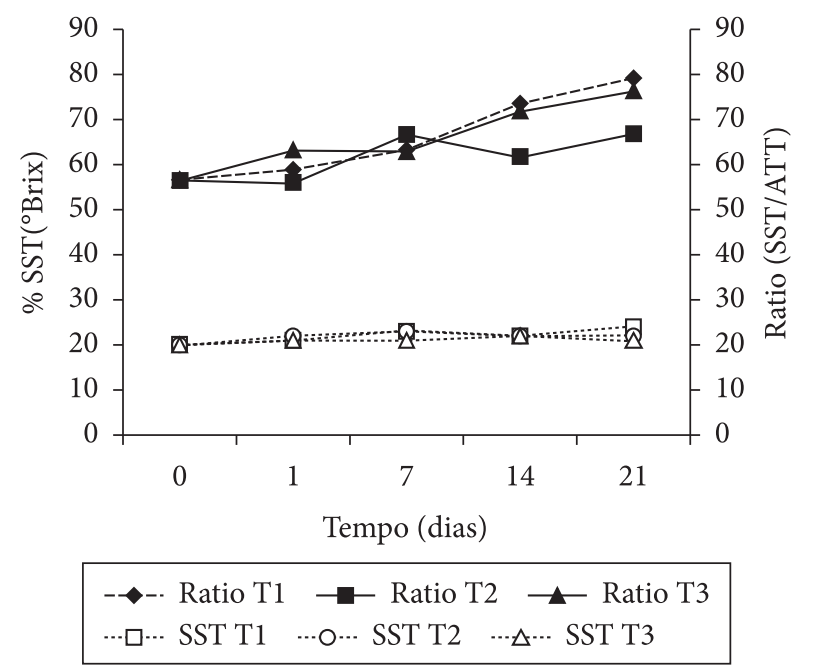

Figura 7. Comportamento da banana, nos três tipos de calda, em relação à variação dos SST e da razão (SST/ATT), durante os 21 dias de armazenamento à temperatura de $6{ }^{\circ} \mathrm{C}$.

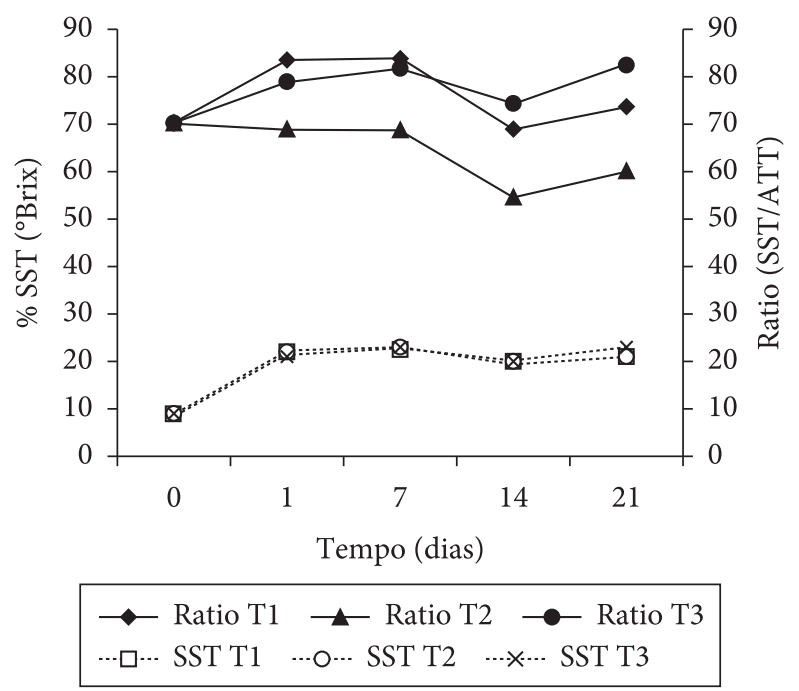

Figura 8. Comportamento do mamão, nos três tipos de calda, em relação à variação dos SST e da razão ou "ratio" (SST/ATT), durante os 21 dias de armazenamento, à temperatura de $6^{\circ} \mathrm{C}$.

desenvolvimento do produto, foi avaliar a sua aceitação pelos consumidores.

A análise de variância das notas de aceitação (CV=14,7\%), no teste sensorial, revelou que não houve interação significativa entre as caldas e os dias de armazenamento e também não houve diferença significativa $(\mathrm{p}<0,05)$ entre as caldas testadas e nem entre os dias (tempo) de armazenamento, ao nível de $5 \%$ de probabilidade. A média geral em torno de 7,4 mostra que todas as saladas obtiveram boa aceitação (entre gostei moderadamente e gostei muito). Este é um dado importante sobre a conservação de sabor durante os 21 dias de armazenamento do produto.

\subsection{Discussão}

Pina et al. (2003), estudando o processamento e a conservação de manga por métodos combinados, comprovaram que a conservação por métodos combinados promoveu estabilidades microbiológicas e sensoriais da manga em pedaços por, no mínimo, 120 dias, à temperatura de $28^{\circ} \mathrm{C}$.

Para estes resultados de preservação sensorial, a calda é o principal fator de conservação. A utilização da calda de sacarose como cobertura pode atuar de diferentes modos; retardar a perda de umidade, atuando como barreira física; proteger o alimento do contato com o oxigênio, evitando, assim, as reações de oxidação; agir como conservante superficial de ação antimicrobiana, reduzindo o pH (LEISTNER, 1992). Durante as reações de oxidação, para evitar a formação de melaninas, pigmentos escuros que prejudicam a aceitação de muitas frutas, deve-se evitar a exposição ao oxigênio, já que este é requerido para iniciar a reação. A utilização de filmes comestíveis pode ser útil para reduzir as taxas de escurecimento (MARTINEZ; WHITAKER, 1995; ARAÚJO, 1999).

Segundo Sanjinéz-Argandoña (1999), o favorecimento da entrada de sólidos solúveis pode diminuir a atividade de água, 
mantendo-se uma consistência aceitável. A atividade de água é uma propriedade que pode ser definida como água disponível para o crescimento microbiano ou demais reações de natureza química, física ou enzimática nos alimentos (FORSYTHE, 2002).

$\mathrm{O}$ valor do $\mathrm{pH}$ pode influir significativamente sobre a vida útil dos alimentos, impedindo a proliferação de microrganismos, como também minimizando o escurecimento enzimático. A maioria dos microrganismos crescem bem em alimentos com valor de $\mathrm{pH}$ em torno de 7,0, enquanto poucos crescem em pH inferior a 4,0 (FORSYTHE, 2002). A combinação dos ácidos naturais das frutas com outros adicionados, como o ácido ascórbico e o ácido cítrico, têm o objetivo de abaixar o pH e também prevenir o escurecimento enzimático. O ácido ascórbico atua reduzindo os compostos do tipo o-quinona formado pela ação das enzimas PPO para a forma fenólica e o ácido cítrico apresenta efeito inibitório duplo sobre as PPO, pois reduzem a atividade enzimática através da redução do $\mathrm{pH}$ e também complexa com o cobre do centro ativo da enzima (ARAÚJO, 1999). O uso do ácido ascórbico como antioxidante, além de ser totalmente seguro para o consumo humano, pode aumentar o teor de vitamina $\mathrm{C}$ de certas frutas e hortaliças (PRESTAMO; MANZANO, 1993).

Além da utilização das boas práticas de fabricação, o armazenamento do produto sob refrigeração contribuiu para sua conservação. O tempo de vida útil difere entre os tipos de produtos minimamente processados, mas varia entre $7 \mathrm{e}$ 20 dias, quando mantidos nas temperaturas recomendadas (WATADA; QI, 1999). O controle da temperatura é importante para a preservação da qualidade dos alimentos, principalmente, para limitar a multiplicação bacteriana, reduzir as atividades enzimáticas, o escurecimento não enzimático e reações de oxidações (FANTUZZI; PUSCHMANN; VANETTI, 2004).

Como na análise sensorial, não houve diferença significativa entre as amostras, pode-se optar por produzir a salada de frutas com formulação de menor custo, ou seja, salada de frutas com menor adição de ácido cítrico $(0,4 \%)$ e maior diluição de suco de maracujá (1:15).

\section{Conclusões}

A salada de frutas foi aprovada enquanto ideia, e considerada como um produto ótimo e original, sendo que $70,9 \%$ dos entrevistados demonstraram interesse em se tornarem futuros consumidores. Os atributos considerados como os mais importantes na hora da decisão de compra foram: preço, referência, necessidade, composição e ingredientes, valores nutricionais.

Ressalta-se que a aplicação de processos mínimos e métodos combinados de conservação elevou a vida de prateleira da salada de frutas, mantendo as características de cor, sabor e aromas. Os resultados apresentados comprovam tal fato e qual obteve aceitação do consumidor, em processo de degustação.
A salada de frutas está pronta para entrar em linha de processo industrial, permitindo sua distribuição e aceitação do consumidor.

\section{Agradecimentos}

À Fundação de Amparo à Pesquisa de Minas Gerais (FAPEMIG) pelo aporte financeiro concedido através do Projeto PAPPE 2006.

\section{Referencias bibliográficas}

ALZAMORA, S. M. et al. Application of combined methods technology in minimally processed fruits. Food Research International, v. 26, n. 2, p. 125-130, 1993.

ARAÚJO, J. M. A. Química de Alimentos: teoria e prática. 2. ed. Viçosa: UFV, 1999. 416 p.

BEHRENS, J. H.; SILVA, M. A. A. P. Atitude do consumidor em relação à soja e produtos derivados. Ciência e Tecnologia de Alimentos, v. 24, n. 3, p. 432-439, 2004.

BRASIL. Ministério da Saúde. Instituto Adolfo Lutz. Normas analíticas do Instituto Adolfo Lutz: métodos químicos e físicos para análise de alimentos. 3. ed. São Paulo, 1985. v. 1.

BRASIL. Ministério do Planejamento, Orçamento e Gestão. Instituto Brasileiro de Geografia e Estatística. Censo demográfico: 2000. Disponível em: <http://www.ibge.gov.br/home/estatistica/ populacao/censo2000/primeiros_resultados_amostra/brasil/pdf/ tabela_1_7_7.pdf.>. Acesso em: 10 nov. 2007.

CHIRIFE, J.; FAVETTO, G. J. Some physico-chemical basis of food preservation by combined methods. Food Research International, v. 25 , p. $389-396,1992$.

COHEN, J. C. Applications of qualitative research for sensory analysis and product development. Food Technology, n. 11, p. 164-174, 1990.

FANTUZZI, E.; PUSCHMANN, R.; VANETTI, M. C. D. Microbiota contaminante em repolho minimamente processado. Ciência e Tecnologia de Alimentos, v. 24, n. 2, p. 207-211, 2004.

FORSYTHE, S. J. Microbiologia da segurança alimentar. Tradução de Maria Carolina Minardi Guimarães; Cristina Leonhardt. Porto Alegre: Artmed, 2002. 424 p.

IAROZINSKI NETO, A.; CANCIGLIERI JUNIOR, O. Identificação de oportunidades para novos produtos: um processo permanente. In: CONGRESSO BRASILEIRO DE GESTÃO E DESENVOLVIMENTO DE PRODUTOS, 4., 2003, Gramado. Anais... Gramado: IEM, 2003. p. 1-10.

JAYARAMAN, K. S. Development of intermediate moisture tropical fruits and vegetables products: technological problems and prospects. In: CANOVAS, B.; GUSTOVA, V. (Eds.). Food preservation by moisture control: fundamentals and applications. Essex: CC Seow, 1988. 175 p.

LEISTNER, L. Food preservation by combined methods. Food Research International, v. 25, n. 2, p. 151-158, 1992.

MARCOS, S. K. Desenvolvimento de tomate de mesa, com o uso do método QFD (quality function deployment), comercializado em um supermercado. 2001. 199 p. Tese (Doutorado) - Universidade Estadual de Campinas, Campinas, 2001.

MARTINEZ, M. V.; WHITAKER, J. R. the biochemistry and control of enzymatic browning. Trends in Food Science and Technology, v. 6, n. 6, 1995. 
MATTIUZ, B.; DURIGAN, J. F.; ROSSI JUNIOR, O. D. Processamento mínimo em goiabas 'Paluma' e 'Pedro Sato': avaliação química, sensorial e microbiológica. Ciência e Tecnologia de Alimentos, v. 23 , n. 3, p. 409-413, 2003.

OHLSSON, T. Minimal processing-preservation methods of the future: an overview. Trends in Food Science \& Technology, v. 5, p. 341-344, 1994.

PINA, M. G. M. et al. Processamento e conservação de manga por métodos combinados. Revista Brasileira de Fruticultura, v. 25, n. 1, p. 63-66, 2003.

PRÉSTAMO, G.; MANZANO, P. Peroxidases of selected fruits and vegetables and the possible use of ascorbic acid as antioxidant. HortScience, v. 28, p. 48-50, 1993.

RAOULT-WACK, A. L.; LENART, A.; GUILBERT, S. Recent advances in the osmotic dehydration of foods. Trends in Food Science \& Technology, v. 5, n. 8, p. 225-260, 1994.

SANJINEZ-ARGANDOÑA, E. J. Desidratação de goiaba (Psidium guajava L.) por imersão e secagem. 1999. 103 p. Dissertação (Mestrado) - Universidade Estadual de Campinas, Campinas.
SARZI, B.; DURIGAN, J. F.; ROSSI JÚNIOR, O. D. Temperatura e tipo de preparo na conservação de produto minimamente processado de abacaxi-pérola. Revista Brasileira de Fruticultura, v. 24, n. 2, p. 376-380, 2002.

SAS INSTITUTE. SAS user's guide: statistics 8.2. Cary, 2001. $1028 \mathrm{p}$.

TADINI, C. C.; SAKUMA, H.; FREITAS, E. Estudo da estabilidade microbiológica do purê de banana de cultivar Musa cavendishii. In: CONGRESSO BRASILEIRO DE CIÊNCIA E TECNOLOGIA DE ALIMENTOS, 16., 1998, Rio de Janeiro. Anais... Rio de Janeiro: SBCTA. p. 1833-1836. Trabalho 304.

VÁSQUEZ, R.; SANTOS, M. L.; ÁLVAREZ, L. I. Market orientation and competitive strategies in industrial firms. Journal of Strategic Marketing, v. 9, p. 69-90, 2001.

WATADA, A. L.; QI, L. Quality of fresh-cut produce. Postharvest Biology and Technology, v. 15, p. 201-205, 1999.

WELTI-CHANES, J.; VERGARA-BALDERAS, F.; LOPEZ-MALO, A. Minimally processed foods: sttate of the art and future. In: FITO, P.; ORTEGA-RODRIGUEZ, E.; WILEY, R. Minimally processed refrigerated fruits \& vegetables. New York: Chapman \& Hall 1994. $368 \mathrm{p}$ 